\title{
Human Brain Language Areas Identified by Functional Magnetic Resonance Imaging
}

\author{
Jeffrey R. Binder, ${ }^{1,2}$ Julie A. Frost, ${ }^{1}$ Thomas A. Hammeke, ${ }^{1}$ Robert W. Cox, ${ }^{3}$ Stephen M. Rao, ${ }^{1,2}$ and \\ Thomas Prieto ${ }^{1}$ \\ Departments of ${ }^{1}$ Neurology and ${ }^{2}$ Cellular Biology and Anatomy, and ${ }^{3}$ Biophysics Research Institute, Medical College of \\ Wisconsin, Milwaukee, Wisconsin 53226
}

Functional magnetic resonance imaging (FMRI) was used to identify candidate language processing areas in the intact human brain. Language was defined broadly to include both phonological and lexical-semantic functions and to exclude sensory, motor, and general executive functions. The language activation task required phonetic and semantic analysis of aurally presented words and was compared with a control task involving perceptual analysis of nonlinguistic sounds. Functional maps of the entire brain were obtained from 30 righthanded subjects. These maps were averaged in standard stereotaxic space to produce a robust "average activation map" that proved reliable in a split-half analysis. As predicted from classical models of language organization based on lesion data, cortical activation associated with language processing was strongly lateralized to the left cerebral hemisphere and involved a network of regions in the frontal, temporal, and parietal lobes. Less consistent with classical models were (1) the existence of left hemisphere temporoparietal language areas outside the traditional "Wernicke area," namely, in the middle temporal, inferior temporal, fusiform, and angular gyri; (2) extensive left prefrontal language areas outside the classical "Broca area"; and (3) clear participation of these left frontal areas in a task emphasizing "receptive" language functions. Although partly in conflict with the classical model of language localization, these findings are generally compatible with reported lesion data and provide additional support for ongoing efforts to refine and extend the classical model.

Key words: language; functional magnetic resonance imaging; brain mapping; semantic; phonological; auditory cortex
Language-related functions were among the first to be ascribed a specific location in the human brain (Broca, 1861) and have been the subject of intense research for well over a century. A "classical model" of language organization, based on data from aphasic patients with brain lesions, was popularized during the late 19th century and remains in common use (Wernicke, 1874; Lichtheim, 1885; Geschwind, 1971; Benson, 1985; Mayeux and Kandel, 1985). In its most general form, this model proposes a frontal, "expressive" area for planning and executing speech and writing movements, named after Broca (Broca, 1861), and a posterior, "receptive" area for analysis and identification of linguistic sensory stimuli, named after Wernicke (Wernicke, 1874). Although many researchers would accept this basic scheme, a more detailed account of language organization has not yet gained widespread approval. There is not universal agreement, for example, on such basic issues as which cortical areas make up the receptive language system (Bogen and Bogen, 1976) or on the specific linguistic role of Broca's area (Marie, 1906; Mohr, 1976).

Noninvasive functional imaging methods are a potential source of new data on language organization in the intact human brain (Petersen et al., 1988; Démonet et al., 1992; Bottini et al., 1994).

Received Aug. 1, 1996; revised Oct. 7, 1996; accepted Oct. 11, 1996.

This work was supported by a grant from the McDonnell-Pew Program in Cognitive Neuroscience, National Institute of Neurological Diseases and Stroke Grant RO1 NS33576, and National Institute of Mental Health Grant PO1 MH51358. We thank J. Hyde, A. Jesmanowicz, W. O'Reilly, and L. Estkowski for discussion and technical assistance.

Correspondence should be addressed to Dr. J. R. Binder, Department of Neurology, Medical College of Wisconsin, 9200 West Wisconsin Avenue, Milwaukee, WI 53226.

Copyright (C) 1996 Society for Neuroscience $0270-6474 / 96 / 170353-10 \$ 05.00 / 0$
Functional magnetic resonance imaging (FMRI) is one such method, which is based on monitoring regional changes in blood oxygenation resulting from neural activity (Ogawa et al., 1990, 1992). Although certain technical issues remain to be resolved, the capabilities of FMRI for localizing primary sensory and motor areas are now well established (Kim et al., 1993; Rao et al., 1993; Binder et al., 1994b; DeYoe et al., 1994; Sereno et al., 1995). Preliminary studies of higher cognitive functions also have been reported, but the validity of the activation procedures used and the reliability of responses in these procedures remain unclear (Hinke et al., 1993; McCarthy et al., 1993; Cohen et al., 1994; Rueckert et al., 1994; Binder et al., 1995; Demb et al., 1995; Shaywitz et al., 1995).

We used FMRI to investigate the cortical regions involved in language processing in normal, right-handed subjects. The linguistic task, which required meaning-based decisions about aurally presented words, was designed to elicit receptive language processing at both phonetic (speech perceptual) and semantic (associative) levels, with the goal of identifying as many candidate "receptive language" areas as possible. A baseline task, which required pitch-based decisions about tone sequences, was used to control for activation of early auditory processors, nonspecific executive functions mediating attention and arousal, and motor response systems. Preliminary studies using this language task demonstrated left hemisphere lateralization of blood oxygenation responses and a strong correlation between this lateralization measure and language lateralization as determined by the intracarotid amobarbital procedure (Binder et al., 1995, 1996b). These preliminary studies investigated individual subject activation patterns only and did not include imaging of medial brain regions. A 
more recent report presented averaged group activation patterns but only for the lateral third of the left hemisphere (Binder et al., 1996a). In the present study, we imaged the entire brain in 30 subjects, merged the spatially normalized data to obtain an average activation pattern, and checked the reliability of this pattern by comparing two matched subgroups from the original sample. As in previous functional imaging studies, the findings are partly in conflict with the classical model of language localization (Petersen et al., 1988; Démonet et al., 1992; Bottini et al., 1994; Damasio et al., 1996) but are generally compatible with a large body of recent lesion data (Damasio, 1981; Kertesz et al., 1982; Freedman et al., 1984; Warrington and Shallice, 1984; Alexander et al., 1989; Hart and Gordon, 1990; Hillis and Caramazza, 1991; Rapcsak and Rubens, 1994; Damasio et al., 1996), suggesting a need to refine and extend the classical model.

\section{MATERIALS AND METHODS}

Subjects. Subjects were 30 healthy adults (15 women, 15 men), ranging in age from 18 to 29 years, with no history of neurological, psychiatric, or auditory symptoms. Edinburgh Handedness Inventory laterality quotients (Oldfield, 1971) ranged from 58 to 100, indicating strong right-hand preferences for all subjects. Subjects were recruited on a voluntary basis, gave written informed consent, and were paid a small hourly stipend. All studies received prior approval by the Medical College of Wisconsin Human Research Review Committee.

Apparatus and scanning procedures. Scanning was conducted at 1.5 Tesla on a General Electric (GE Medical Systems, Milwaukee, WI) Signa scanner using a three-axis local gradient coil with an insertable transmitreceive radiofrequency coil optimized for whole-brain echo-planar imaging (EPI). Functional imaging used a gradient-echo EPI sequence with the following parameters: $40 \mathrm{msec}$ echo time, $4 \mathrm{sec}$ repetition time, $24 \mathrm{~cm}$ field of view, $64 \times 64$ pixel matrix, and $3.75 \times 3.75 \times 7.0 \mathrm{~mm}$ voxel dimensions. Seventeen to 19 contiguous sagittal slice locations were imaged, encompassing the entire brain. One-hundred sequential images were collected at each of the slice locations. High-resolution, T1weighted anatomical reference images were obtained as a set of 124 contiguous sagittal slices using a three-dimensional spoiled-gradient-echo sequence (SPGR, GE Medical Systems, Milwaukee, WI).

Subjects were scanned with eyes closed and room lights dimmed. Padding was placed behind the neck and around the head as needed to relax the cervical spine and to pack the space between the head and inner surface of the coil. This padding minimizes the range of motion that can occur and provides tactile feedback for subjects who are attempting to remain motionless. Each 100-image EPI series began with four baseline images $(16 \mathrm{sec})$ to allow magnetic resonance (MR) signal to reach equilibrium, followed by 96 images during which two comparison conditions were alternated every $24 \mathrm{sec}$. Each image series thus consisted of eight task alternation cycles (12 images/cycle).

Stimuli and activation tasks. Stimuli were 16-bit digitally synthesized tones and sampled male speech sounds presented binaurally at precise intervals using a computer playback system. Sounds were amplified near the scanner using a magnetically shielded transducer system and were delivered to the subject via air conduction through $180 \mathrm{~cm}$ paired plastic tubes. The tubes were threaded through tightly occlusive ear inserts that attenuated background scanner noise to $\sim 75 \mathrm{~dB}$ sound pressure level (SPL). Background scanner noise was constant throughout all rest and task conditions. Intensity of the experimental stimuli averaged $100 \mathrm{~dB}$ SPL and remained constant across all subjects and all stimuli. Subjects reported that the experimental stimuli were subjectively louder than the background scanner noise.

Comparison conditions included an unspecified "rest" state and two explicit behavioral tasks. For the rest condition, subjects were instructed to remain relaxed and motionless but were given no other instructions or stimuli. The behavioral tasks were designed to direct subjects' attention either to physical characteristics of nonlinguistic stimuli ("tone decision") or to semantically related information pertaining to linguistic stimuli ("semantic decision"). The rationale for these tasks was given previously (Binder et al., 1995) and will be briefly summarized. First, it is hypothesized that a variety of general-purpose, nonlinguistic functional systems are activated during most language behaviors. These could include early sensory processors, motor systems, short-term memory systems, and attention-arousal networks. Although vital to language behavior, these systems are not the focus of interest of this study insofar as they are also activated during nonlinguistic behaviors. Second, it is known that a considerable amount of "automatic" processing of linguistic stimuli takes place at phonological and semantic levels regardless of the behavioral situation in which stimulus presentation occurs (Carr et al., 1982; Marcel, 1983; Van Orden, 1987; Price et al., 1996). The nonlinguistic comparison task used in this study (tone decision) was therefore designed to (1) control for activation of sensory, motor, and general-purpose executive systems; and (2) accomplish this with minimal "automatic" activation of language systems.

Stimuli in the tone decision task were 500 and $750 \mathrm{~Hz}$ pure tones, with a duration of $150 \mathrm{msec}$ and $5 \mathrm{msec}$ onset and offset envelopes. These were presented as sequences of three to seven tones, with $250 \mathrm{msec}$ of silence separating each tone in a sequence and $1000 \mathrm{msec}$ separating each sequence. Sequences contained an average of five tones, resulting in an average total stimulus duration of $750 \mathrm{msec}$. Subjects were required to respond by button press for any sequence containing two $750 \mathrm{~Hz}$ tones. Stimuli in the semantic decision task were spoken English nouns designating animals (e.g., "turtle"). These words had an average usage frequency of 9.3 per million (SD 26.2, range 0-203) (Francis and Kucera, 1982 ) and contained an average of 5.2 phonemes (SD 2.0, range 2-10). Each animal word was used only once during the entire imaging session. Stimuli were edited to an average duration of $750 \mathrm{msec}$ and were followed by a $2250 \mathrm{msec}$ interstimulus interval. Subjects were required to respond by button press for animals they considered to be both "native to the United States" and "used by humans." The tasks were matched on stimulus intensity, average stimulus duration per trial $(750 \mathrm{msec})$, average trial duration $(3 \mathrm{sec})$, and frequency of positive targets $(1 \mathrm{target} / 8 \mathrm{sec})$. Responses consisted of a thumb press to a hand-held button device placed in the subject's left hand. Button responses produced a visual signal in the control room that was used to log performance accuracy.

Two functional image series were acquired. In the tone decision-rest comparison, subjects performed the tone decision task eight times, with eight intervening epochs of rest. In the semantic decision-tone decision comparison, subjects performed the semantic decision task eight times with eight intervening periods of tone decision. Instructions and brief practice trials on each task were given before scanning.

Data analysis. To compensate for artifactual signal intensity changes caused by head movement, a modified version of the automated image registration program developed by Woods et al. (Woods et al., 1992) was used to register the EPI images within each time series. This program uses an iterative procedure to minimize the variance in voxel intensity ratios of two images. In the present study, images 5-100 in each time series were registered with image 4 , and only these images were used in additional analyses. Each registered 96-image series was then viewed as a cine loop to detect residual visible head motion. Images showing such motion made up $<2 \%$ of the total acquired data and were not included in subsequent analyses. No 96-image series contained more than four motion-contaminated images.

For each functional time series, $t$ tests were conducted at each voxel to measure changes in signal intensity between comparison conditions. For the purposes of this analysis, one of the comparison conditions was designated the activation, or "probe," condition and the other the "control" condition. First, the final four images within each of the eight probe epochs were averaged to produce an image of average signal intensity values during the last $12 \mathrm{sec}$ of each probe epoch. This procedure ensured that the measured values would reflect steady-state activation levels after completion of the hemodynamic response (Binder et al., 1995). Next, the final four images obtained during control epochs before and after each probe epoch were averaged, and a probe-control difference image was created for each activation cycle by subtracting the average control image from the corresponding average probe image (Binder et al., 1994a). This use of a "local baseline" lessens the effects of signal instability caused by scanner "drift" and low-frequency spontaneous oscillations. Finally, these mean probe-control difference values were compared, on a voxel-by-voxel basis, against a hypothetical mean of zero using pooled-variance Student's $t$ tests. This procedure generates statistical parametric maps (SPMs) of $t$ deviates reflecting differences between probe and control states at each voxel location for each subject. For the sake of simplicity, such differences are referred to below as "activation."

Individual anatomical (SPGR) scans and SPMs were then transformed into the standard stereotaxic space of Talairach and Tournoux (1988), using the MCW-AFNI software package (Cox, 1996). This procedure involves marking fiducial points on the high-resolution anatomical scans at the anterior commissure, posterior commissure, midsagittal plane, and 
brain edges. To compensate for normal variation in anatomy across subjects (Toga et al., 1993), the unthresholded, stereotaxically resampled three-dimensional SPMs were smoothed slightly with a Gaussian filter of root-mean-square radius $4 \mathrm{~mm}$. These data sets were then merged across subjects by averaging the $t$ statistics in each voxel. The procedure of averaging statistics was chosen to guard against nonequal MR signal variances among subjects. This heteroscedasticity could arise from many causes; differing degrees of subject motion, differing amounts of cardiacinduced tissue pulsatility, and variability in the scanner between sessions are three likely sources. The averaged $t$ statistics were then thresholded to identify voxels in which the mean change in MR signal between comparison conditions was unlikely to be zero. The average of a set of $t$ deviates is not a tabulated distribution. Therefore, the Cornish-Fisher expansion of the inverse distribution of a sum of random deviates was used to select a threshold for rejection of the null hypothesis (Fisher and Cornish, 1960). Only average $t$ scores $\geq 0.875$ were considered significant $(p<$ $0.0001)$.

Individual three-dimensional SPGR data from the 30 subjects were also merged to produce an "average brain" for anatomical reference. Anatomical labels for activated areas were derived by interactive threedimensional inspection of stereotaxically registered functional and anatomical data using MCW-AFNI software (Cox, 1996) and by reference to the atlas of Talairach and Tournoux (1988). Activated regions were typically large expanses of cortex following gyral and sulcal topography rather than small foci and were thus more completely described by reference to anatomical structures than in terms of point coordinates. Activation areas were given anatomical labels only when the borders of the area followed borders of a gyral or sulcal structure in the Talairach and Tournoux atlas and the label was supported by three-dimensional inspection of the averaged anatomical data.

A split-half procedure was used to estimate how well the semantic decision-tone decision activation pattern would generalize to other subject samples, analogous to the use of this procedure in test theory for estimating item homogeneity (Crocker and Algina, 1986). Subjects were divided into two independent samples of 15 subjects each, matched on gender, age, and handedness. Individual subject SPMs from the semantic decision-tone decision comparison were averaged within each subgroup. These average SPMs were then correlated on a voxel-by-voxel basis after masking voxels in nonbrain regions of the image, yielding a reliability coefficient for the two halves of the total sample. A reliability coefficient for the activation pattern obtained from the entire sample of 30 subjects was then estimated using the Spearman-Brown prophecy formula, $\rho_{\mathrm{XX}}=$ $2 \rho_{\mathrm{AB}} /\left(1+\rho_{\mathrm{AB}}\right)$, where $\rho_{\mathrm{XX}}$ is the estimated reliability coefficient for the entire sample, and $\rho_{\mathrm{AB}}$ is the split-half correlation (Spearman, 1910). Finally, a visual comparison of the location of activation peaks in each subgroup was made after thresholding each subgroup SPM at an average $t$ score of $1.30(p<0.0001)$.

\section{RESULTS}

\section{Task performance}

All subjects learned the tasks easily and tolerated the scanning procedure well. Performance on the tone decision task was uniformly good, with subjects attaining an average score of $98.3 \%$ correct (range, 89-100\%). Responses by each subject on the semantic decision task were compared with those given by a group of 50 normal right-handed controls on the same stimulus set. Items responded to with a probability $>0.75$ by controls were categorized as targets, and items responded to with a probability $<0.25$ by controls were categorized as foils. Subjects' percent correct scores in discriminating targets from foils averaged $92.6 \%$ (range, 73-100\%).

\section{Tone-task activation}

Compared with the resting state, performance of the tone task produced blood oxygenation changes in multiple areas of both cerebral hemispheres, cerebellum bilaterally, bilateral deep nuclei, and brainstem (Fig. 1). The superior temporal gyri (STG) were activated bilaterally. This activation extended throughout much of the STG, including Heschl's (transverse temporal) gyrus, the superior temporal plane posterior and anterior to Heschl's gyrus, and much of the lateral surface of the STG excluding cortex near the anterior aspect of the superior temporal sulcus (STS). Activation in the STG did not spread ventrally beyond the STS in the left hemisphere but did so in the right hemisphere, involving the posterior half of the middle temporal gyrus (MTG). Activation of the superior temporal plane anterior to Heschl's gyrus (planum polare) did not include temporal cortex adjacent to the insula and did not spread to adjacent insular cortex. In both hemispheres, activation spread posteriorly along the planum temporale and the lower bank of the posterior ascending ramus of the sylvian fissure (planum parietale) and into the surrounding supramarginal gyrus. This activation of the supramarginal gyrus was much more extensive in the right hemisphere.

Activation also involved the inferior, middle, and superior frontal gyri bilaterally. In the left hemisphere, this followed the length of the precentral sulcus, involving (premotor) cortex on either side of this sulcus. Right hemisphere frontal activation was also observed along the length of the precentral sulcus but also extended anteriorly to involve the pars opercularis, portions of the pars triangularis, and prefrontal cortex along the inferior frontal sulcus and in the middle frontal gyrus. In both hemispheres, there was activation of anterior insular cortex underneath the activated region of frontal operculum. Activation of the superior frontal gyrus involved a region just anterior to the paracentral lobule, probably representing the supplementary motor area (SMA) bilaterally $(x= \pm 6, y=-5, z=61)$. In both hemispheres, this SMA focus was contiguous laterally with the activation centered on the precentral sulcus and was contiguous ventrally with an area of activation in the midanterior cingulate gyrus. Activation in all these frontal lobe areas was somewhat more extensive in the right hemisphere. A small activation focus was present in the region of the right central sulcus, approximately at the site of motor representation for the left hand.

Subcortical activation was observed bilaterally in the anterior putamen, genu of the internal capsule, thalamus, and dorsal midbrain. Activation in these structures was also somewhat more prominent on the right. Details of these subcortical activations will be the subject of a subsequent report. The posterior and lateral cerebellum was activated bilaterally, more extensively on the left.

In summary, the tone task was associated with bilateral activation of multiple cortical areas including primary and association auditory cortex of the STG, supramarginal gyrus, premotor cortex and SMA, anterior cingulate, and anterior insula. The right supramarginal gyrus was clearly more active than the left. The MTG and several prefrontal areas were activated in the right hemisphere only.

\section{Language areas}

Areas that were activated more strongly by the semantic decision task than by the tone task were defined as language areas and were found almost exclusively in the left hemisphere or in the right cerebellum (Fig. 2). In contrast to the tone task, which activated the left STG but not MTG, the semantic decision task activated cortex on both sides of the STS and most of the MTG in the left hemisphere. This activation also spread ventrally across portions of the inferior temporal gyrus (ITG) and fusiform and parahippocampal gyri in the ventral temporal lobe. In contrast, several other temporal lobe areas responded more strongly to the tone task than to the semantic task (i.e., showed relative signal "decreases" during the semantic task). These included the planum temporale bilaterally and the posterior MTG in the right hemi- 
Figure 1

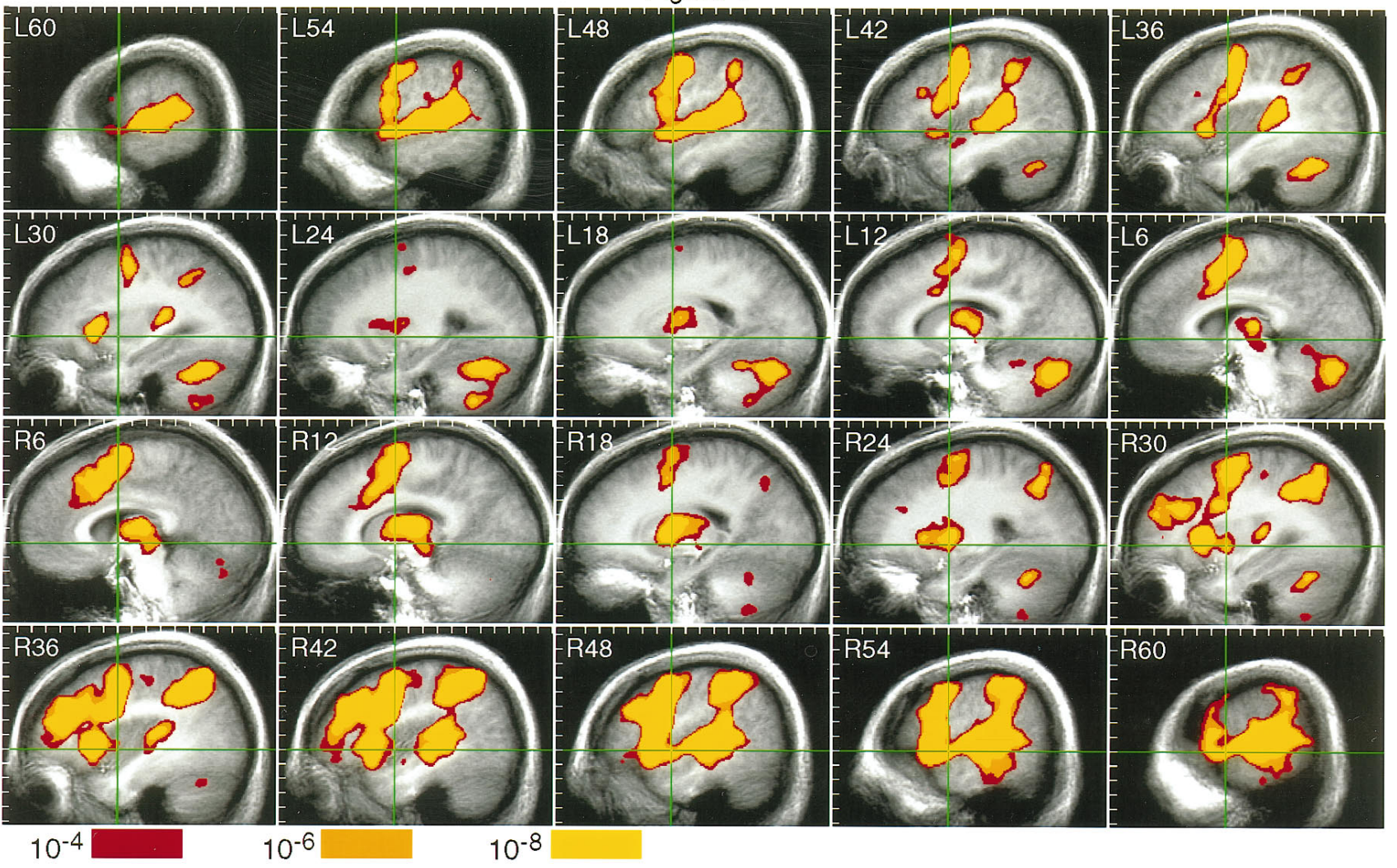

Figure 2

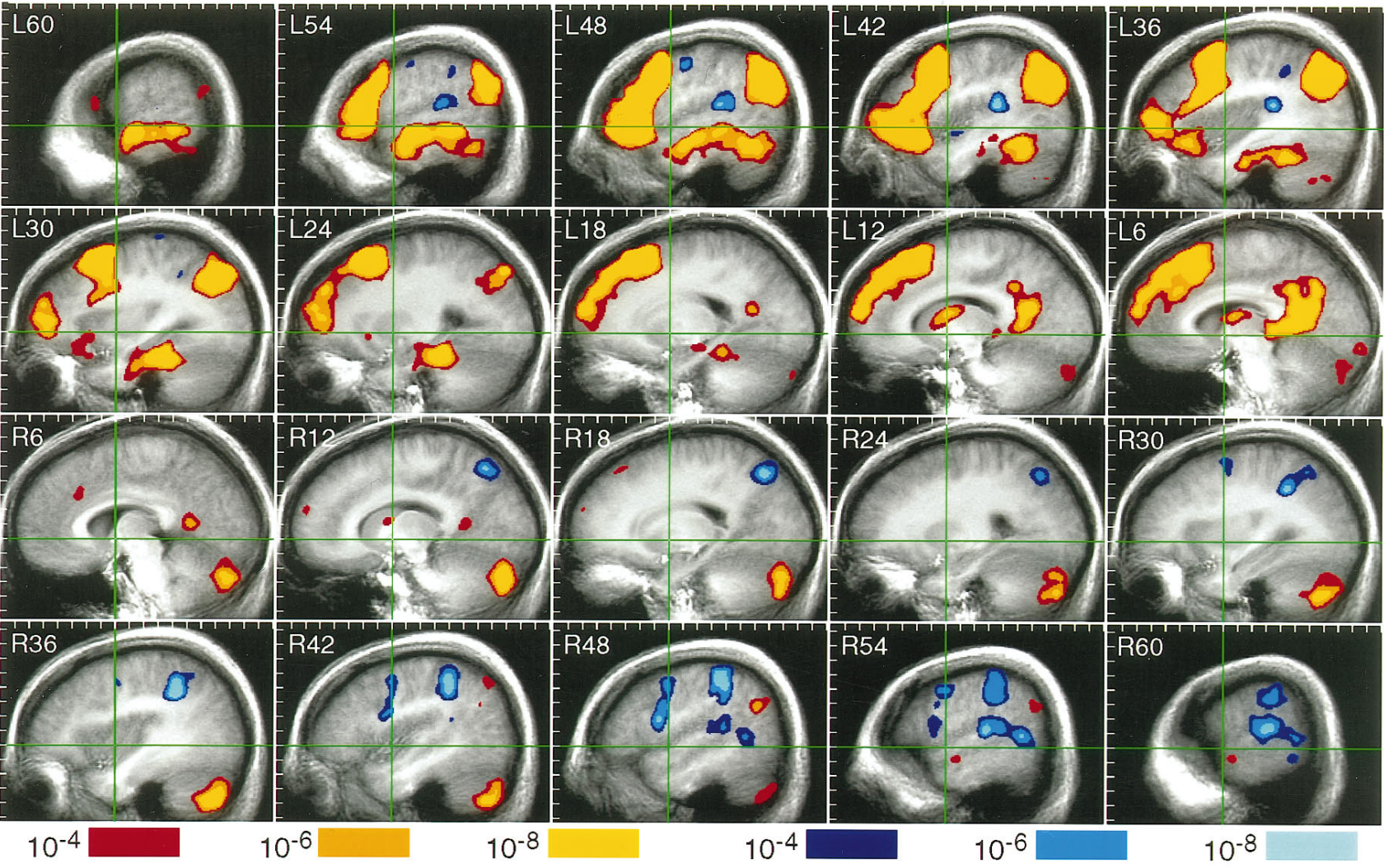


sphere. The other bilateral STG (auditory) areas that had been activated by the tone task relative to rest showed no difference in level of activation by the tone and semantic tasks.

Virtually the entire inferior frontal gyrus (IFG) was activated by the semantic decision task, including pars opercularis, pars triangularis, pars orbitalis, and cortex along the inferior frontal sulcus. Rostral and caudal areas of the middle frontal gyrus were active, whereas the midportion of this gyrus (approximately Brodmann area 9) was not. Much of the superior frontal gyrus anterior to the vertical AC line demonstrated activation, including the pre-SMA and medial aspect of Brodmann areas 8-10 (Picard and Strick, 1996). Left medial frontal activation also spread ventrally to involve part of the anterior cingulate gyrus. This overlapped but was mostly rostral to the cingulate region activated by the tone task. Much smaller anterior cingulate and superior frontal gyrus activations were observed in the right hemisphere. The SMA and premotor cortex along the precentral sulcus were not activated by the semantic task more than the tone task; premotor cortex of the right hemisphere and a small area of dorsolateral premotor cortex in the left hemisphere responded more strongly to the tone task.

A third major focus of activation by the semantic task was in the left angular gyrus. A much smaller angular gyrus activation was observed in the right hemisphere. These areas were immediately posterior to the planum temporale and supramarginal gyrus foci that had been activated by the tone task. Like the planum temporale, the supramarginal gyrus in both hemispheres was more strongly activated by the tone task than the semantic task.

A fourth large cortical region activated by the semantic task involved the posterior cingulate gyrus, a portion of the precuneus, retrosplenial cortex, and cingulate isthmus in the left hemisphere. A much smaller retrosplenial activation was present in the right hemisphere. Deep structures activated by the semantic task relative to the tone task included a portion of the caudate nucleus, anterior internal capsule, and anterior thalamus in the left hemisphere only. Semantic task activation involved a large part of the posterior right cerebellum. A much smaller activation was observed near the posterior midline of the left cerebellum.

In summary, four distinct cortical language-related areas were observed in the left hemisphere. These were: (1) a lateral and ventral temporal lobe region that included STS, MTG, and parts of the ITG and fusiform and parahippocampal gyri; (2) a prefrontal region that included much of the inferior and superior frontal gyri, rostral and caudal aspects of the middle frontal gyrus, and a portion of the anterior cingulate; (3) angular gyrus; and (4) a perisplenial region including posterior cingulate, ventromedial precuneus, and cingulate isthmus. These regions were clearly distinct from auditory, premotor, SMA, and supramarginal gyrus areas that had been bilaterally activated by the tone task. The other large region activated by the semantic task was the right posterior cerebellum.

\section{Reliability of language activation patterns}

The pattern of language activation observed in the group average was also visible in the individual subjects' data, as exemplified by the subject shown in Figure 3. Language activation patterns were very similar in the two matched samples of 15 subjects (Fig. $4 A, B)$. Although the overall level of activation was somewhat greater in subgroup 2 (Fig. $4 B$ ), the four left hemisphere language regions in the temporal lobe, frontal lobe, angular gyrus, and perisplenial cortex were clearly evident in both subgroups, as was the focus in right posterior cerebellum. Voxel-by-voxel correlation between the activation maps from the two subgroups was 0.86 , and the Spearman-Brown estimated reliability coefficient for the entire sample of 30 subjects was 0.92 . This result indicates the level of correlation that would be expected between the activation pattern from this sample and activation patterns from other random samples of 30 subjects matched to this sample on age, handedness, and gender.

\section{DISCUSSION}

This FMRI study sought to identify candidate language processing areas in the intact human brain and to distinguish these from nonlanguage areas. The language activation task emphasized perceptual analysis of speech sounds ("phonetic processing") and retrieval of previously learned verbal information associated with the speech sounds ("semantic processing"). Because this task used linguistic stimuli (single words), there may also have been automatic activation of other neural codes related to linguistic aspects of the stimuli, such as those pertaining to orthographic and syntactic representations. By comparing this task with a nonlanguage control task, areas activated equally by both tasks, such as those involved in low-level auditory processing, maintenance of attention, and response production, were "subtracted" from the resulting activation map, revealing areas likely to be involved in language processing. Empirical support for this interpretation comes from a study showing very close correspondence between this FMRI language measure and language lateralization data obtained from intracarotid amobarbital injection (Binder et al., 1996b). The observed language activation pattern appears to be

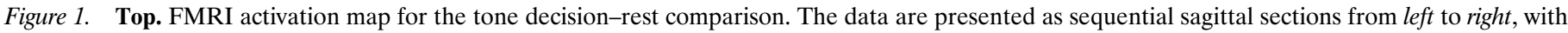

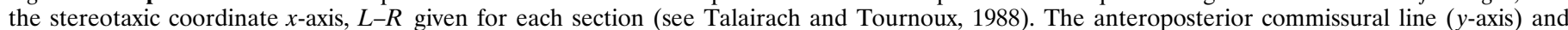

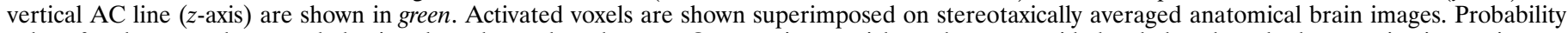

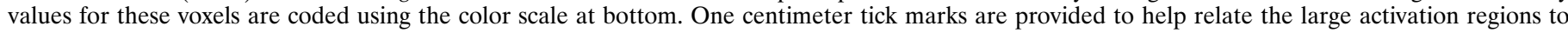

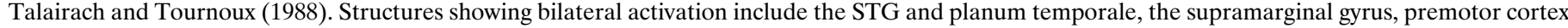

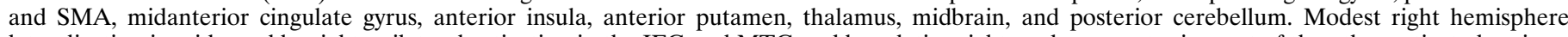

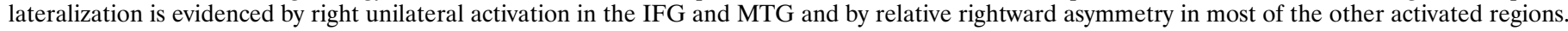

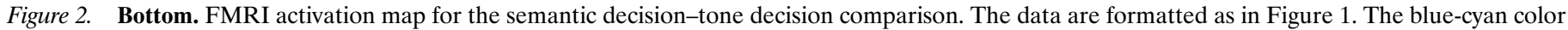

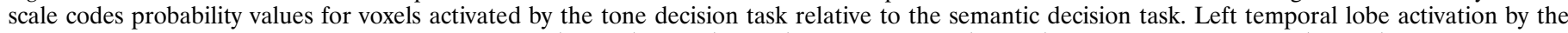

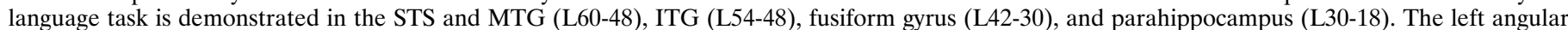

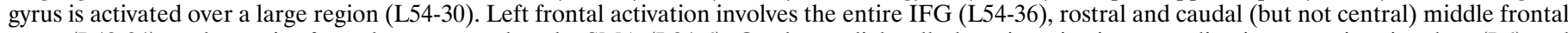

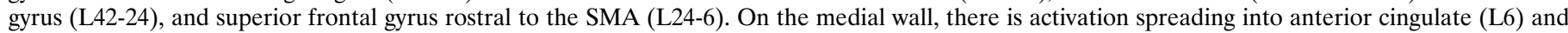

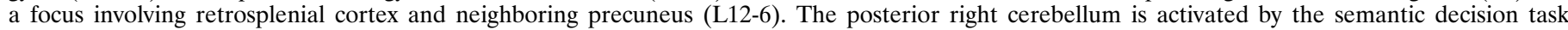

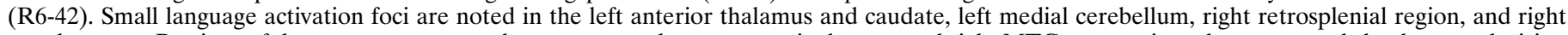

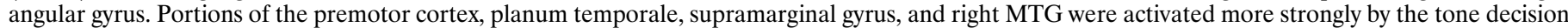
(control) task (i.e., showed relative signal "decreases" during the semantic decision task). 
Figure 3

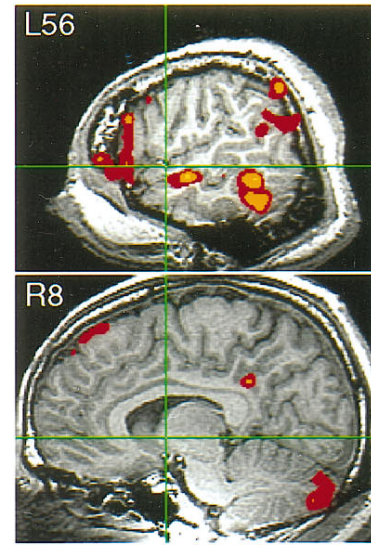

$5 \times 10^{-3}$
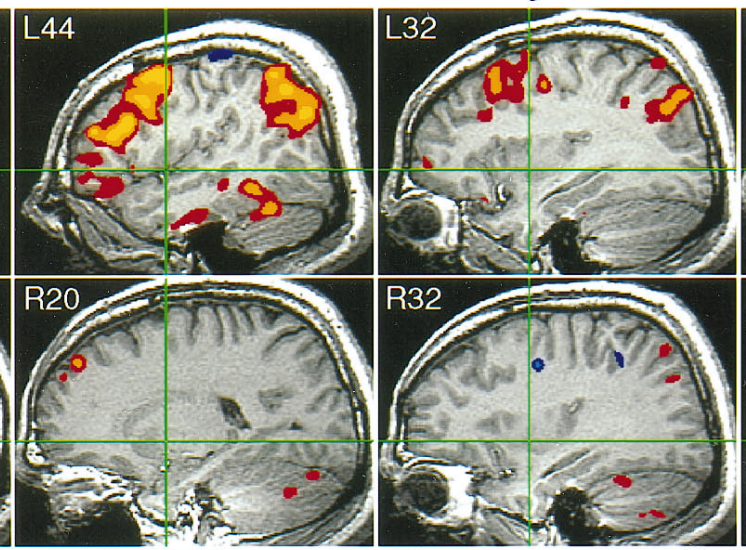

$5 \times 10^{-5}$

$5 \times 10^{-3}$
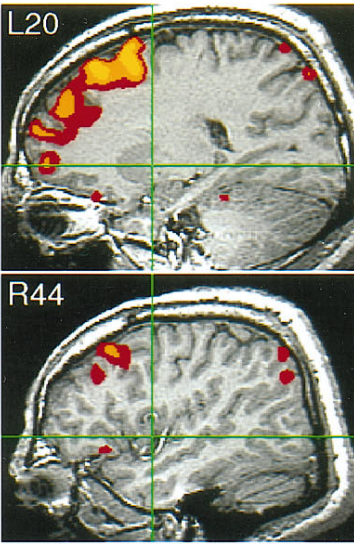

$5 \times 10^{-4}$
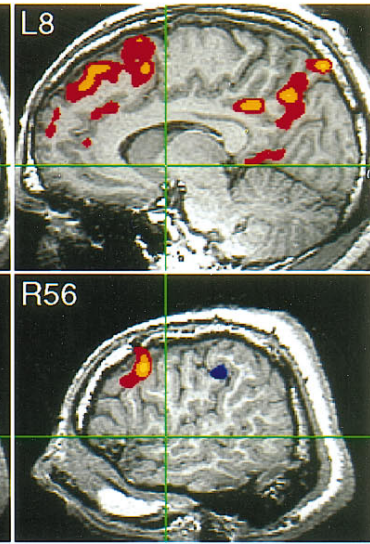

$5 \times 10^{-5}$

Figure 4A
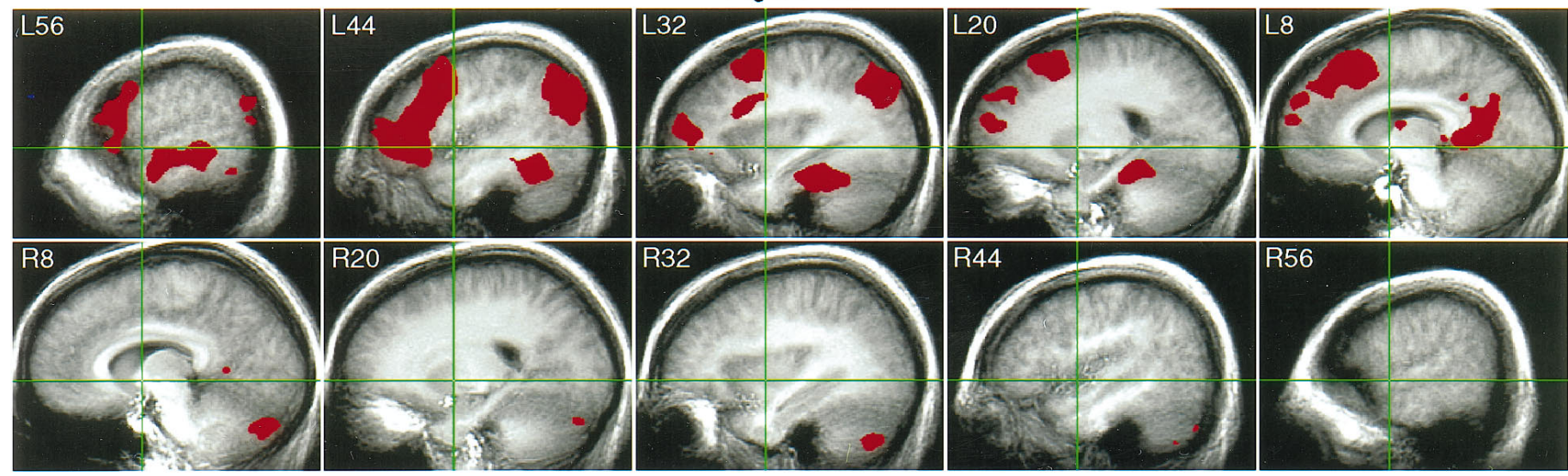

Figure 4B
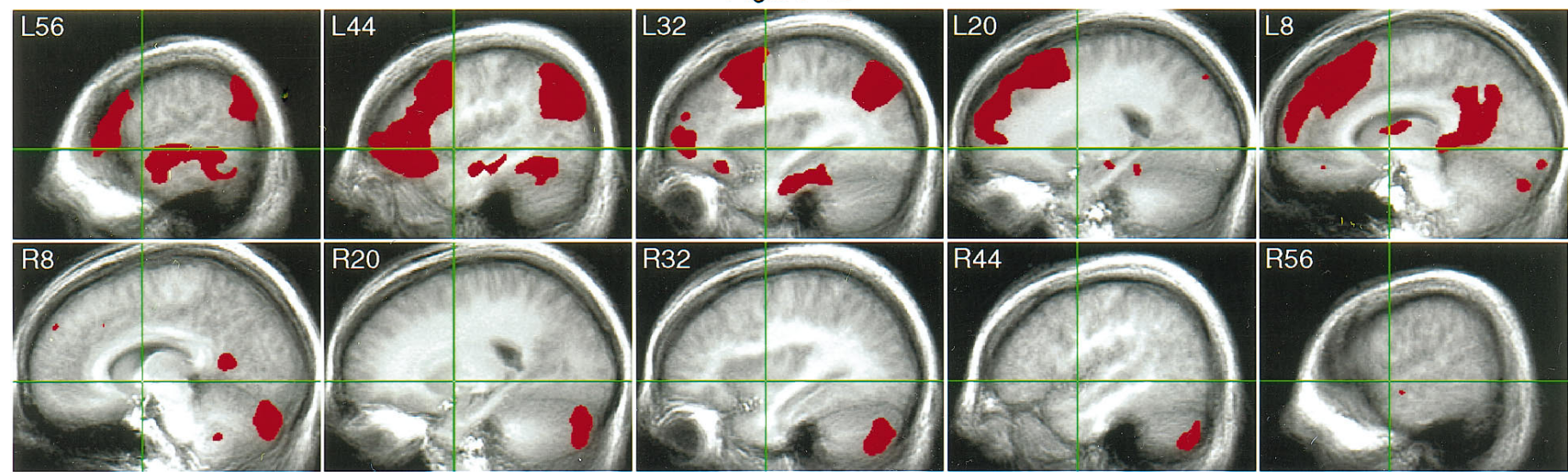

Figure 3. Top. Language areas identified in a 26-year-old male subject. Activated areas in the left hemisphere include STS and MTG (L56), ITG (L56-44), fusiform gyrus (L44), angular gyrus (L56-32), IFG (L56-44), rostral and caudal middle frontal gyrus (L44-32), superior frontal gyrus (L20-8), anterior cingulate (L8), and perisplenial cortex/precuneus (L8). The right posterior cerebellum is activated, as are small foci in right dorsal prefrontal cortex and right angular gyrus.

Figure 4. Bottom. Reproducibility of FMRI language activations. Areas activated by the semantic decision task at a $p<0.0001$ level are displayed in red for subgroup $1(A)$ and subgroup $2(B)$. Background images were obtained by merging anatomical data within each group. The activation patterns are qualitatively very similar in the two groups and are strongly correlated $(\rho=0.86)$.

reliable, in that essentially the same result was obtained from two smaller, matched samples.

This "language map" differs in important respects from the classical model of language localization, which views Broca's area,
Wernicke's area, and the connections between these areas as the primary or core language system. In the following paragraphs, we very briefly discuss points of agreement among the FMRI data, lesion data, and previous functional imaging studies, which indi- 
cate the need for at least some revision to this classical model. These converging sources all suggest that (1) Wernicke's area, although important for auditory processing, is not the primary location where language comprehension occurs; (2) language comprehension involves several left temporoparietal regions outside Wernicke's area, as well as the left frontal lobe; and (3) the frontal areas involved in language extend well beyond the traditional Broca's area to include much of the lateral and medial prefrontal cortex.

\section{Language comprehension and Wernicke's area}

Isolated damage to the left STG (Wernicke's area) probably does not produce multimodal language comprehension deficits (Henschen, 1920-1922). STG lesions, even when fairly extensive and involving adjacent MTG, result instead in the syndrome of pure word deafness, in which there is a defect in decoding the complex acoustic signals in speech but preserved comprehension of language at a semantic level (Barrett, 1910; Henschen, 1918-1919; Kanshepolsky et al., 1973; Tanaka et al., 1987). These observations are consonant with functional imaging data, which demonstrate that the STG is activated bilaterally by both speech and complex nonspeech sounds, and that this activation is modulated neither by the semantic content ("meaningfulness") of stimuli nor by the type of cognitive task performed by the subject (Wise et al., 1991; Binder et al., 1994a,b, 1996a; Millen et al., 1995).

In contrast, multimodal comprehension disturbances, involving both auditory and visual material, are typically associated with large lesions extending beyond the STG and including the MTG, angular, and supramarginal gyri (Kertesz et al., 1979, 1993; Naeser et al., 1981; Selnes et al., 1984; Damasio, 1989; Metter et al., 1990). Isolated angular gyrus lesions are well known to produce language deficits, particularly for written material (Dejerine, 1892; Marie, 1917; Henschen, 1920-1922; Nielsen, 1946; Penfield and Roberts, 1959; Geschwind, 1965). An increasing number of imaging studies confirm that isolated lesions of the left MTG and ITG produce multimodal comprehension deficits (Damasio, 1981; Kertesz et al., 1982; Alexander et al., 1989). A striking feature of some of these cases is the selective nature of the linguistic disturbance, which may affect only a particular lexical-semantic category or word class, leading to the hypothesis that it is the stored knowledge or selective retrieval mechanism related to these categories or classes that is lost as a result of the lesion (Warrington and Shallice, 1984; Hart and Gordon, 1990; Hillis and Caramazza, 1991; Damasio and Tranel, 1993; Damasio et al., 1996).

Data obtained from invasive electrophysiology also confirm the existence of language areas in the lateral and ventral left temporal lobe, including the fusiform gyrus (Penfield and Roberts, 1959; Ojemann et al., 1989; Lüders et al., 1991; Hart et al., 1992; Nobre et al., 1994). Finally, many positron emission tomographic (PET) studies demonstrate activation associated with language processing in left temporoparietal regions outside the STG, including the angular gyrus, MTG, and ITG (Frith et al., 1991; Démonet et al., 1992; Howard et al., 1992; Bottini et al., 1994; Raichle et al., 1994; Bookheimer et al., 1995; Damasio et al., 1996; Fiez et al., 1996; Price et al., 1996; Warburton et al., 1996). The location of left temporoparietal activations in these various reports agrees quite closely with the results of the present study, a somewhat surprising outcome given the diversity of language tasks used by the different investigators.

In summary, converging evidence from lesion and functional imaging research suggests that the left STG plays an important role in analyzing speech sounds. However, this region has been somewhat overemphasized in traditional neuroanatomical models of language processing to the exclusion of large temporoparietal regions in the left hemisphere that probably play a more important role in comprehension at a linguistic-semantic level. These areas include, but may not be limited to, the angular gyrus, MTG, ITG, and fusiform gyrus (approximately Brodmann areas 39, 21, 20, 37, and 36).

\section{Frontal lobe language areas}

Lesions confined to Broca's area (i.e., the posterior left IFG, variously including the pars opercularis, pars triangularis, or both) typically cause apraxic deficits of articulation, with, at most, a transient disturbance of language (Mohr, 1976; Mohr et al., 1978). In contrast, the linguistic deficits characterizing Broca's aphasia are associated with much larger lesions, usually involving the anterior IFG, middle frontal gyrus, insula, ventral pre- and postcentral gyri, or anterior parietal areas in addition to Broca's area (Mohr, 1976; Mohr et al., 1978). Aphasic disorders also occur after left frontal lesions entirely outside Broca's area, in dorsolateral prefrontal cortex and in the superior frontal gyrus (Rubens, 1976; Freedman et al., 1984; Rapcsak and Rubens, 1994). Linguistic deficits reported in such patients include impaired comprehension for syntactically complex material, agrammatism, verbal paraphasia, inability to formulate narrative discourse, and a striking inability to generate word lists (Rubens, 1976; Alexander and Schmitt, 1980; Freedman et al., 1984; Stuss and Benson, 1986; Costello and Warrington, 1989). Together, these data indicate the existence of language cortex in several prefrontal regions outside Broca's area.

Extensive left frontal activation during language processing is a frequent finding in PET research (Frith et al., 1991; Wise et al., 1991; Démonet et al., 1992; Raichle et al., 1994; Fiez et al., 1996; Price et al., 1996). Activation involving all three frontal gyri and anterior cingulate, similar to our results, was noted in a few instances (Bottini et al., 1994; Bookheimer et al., 1995; Warburton et al., 1996), whereas other studies showed IFG activation extending into the posterior middle frontal gyrus, with a separate focus in the medial frontal lobe (Wise et al., 1991; Raichle et al., 1994; Price et al., 1996). A striking finding in the present study was that although language activation involved much of the left prefrontal cortex, a large region in the center of the middle frontal gyrus (approximately Brodmann area 9) was not activated, suggesting that this area has functions clearly distinct from those of other prefrontal areas.

Although the left frontal lobe is traditionally understood as having "expressive" or "output" functions, our study and several others demonstrated left frontal activation during receptive language tasks with little or no requirement for speech production (Démonet et al., 1992; Bottini et al., 1994; Price et al., 1996). The classical view of frontal lobe language function arose from lesion studies, most of which were conducted well after the acute illness and were intended to reveal the areas "critical" for a given function. Functional imaging techniques, in contrast, do not distinguish critical areas from those that participate in a function but can be compensated by other areas. Left frontal regions may participate in receptive language processing in the normal, uninjured state, playing a "language executive" role in coordinating the sensory and semantic processes occurring in posterior areas and accommodating moment-by-moment shifts in goals and strategies. After left frontal injury, it is possible that many of these coordinating functions are taken over by other areas. This would explain the observation that patients with large left frontoparietal 
lesions usually manifest global aphasia and significant comprehension disturbances in the acute period after injury, only later evolving into the typical "expressive" aphasia syndrome (Mohr, 1976; Mohr et al., 1978).

\section{Other activated areas}

Functional activation of the right cerebellum during word generation tasks is a consistent finding in PET studies that include the cerebellum (Petersen et al., 1989; Pardo and Fox, 1993; Raichle et al., 1994). The present data extend this observation to a semantic decision task that does not require word retrieval. The cerebellum may play a general role in facilitating complex neural computations (Keele and Ivry, 1990; Leiner et al., 1991), although the precise nature of this role remains somewhat speculative. Several patients were reported to show cognitive deficits in association with cerebellar damage (Bracke-Tolkmitt et al., 1989; Fiez et al., 1992), yet frank aphasic disturbances are rare.

A major activation during the semantic decision task occurred near the splenium of the corpus callosum. Much of this region probably coincides with retrosplenial cortex (Vogt, 1976), which has connections with hippocampus, parahippocampus (Mufson and Pandya, 1984; Suzuki and Amaral, 1994), and anterolaterodorsal thalamus (Sripanidkulchai and Wyss, 1986). This connectivity pattern suggests an involvement in memory functions, and left hemisphere lesions in this general region reportedly cause a verbal amnestic syndrome (Valenstein et al., 1987; Rudge and Warrington, 1991). Retrosplenial activation may therefore be related to memoryencoding processes that accompanied performance of the semantic decision task. Although identification of memory systems was not an intended goal, processing at a semantic level is known to enhance storage of episodic memories compared with processing at a perceptual level (Craik and Lockhart, 1972). Thus, the episodic memory encoding system was likely activated during the semantic task relative to the tone task. This interpretation could also account for the activation observed in left parahippocampus, another structure closely tied to memory function (von Cramon et al., 1988; ZolaMorgan et al., 1989).

The supramarginal gyrus was activated bilaterally by the tone decision task relative to the semantic decision task and, therefore, was not considered to be a language area. This finding deserves comment, because the left supramarginal gyrus is usually considered part of the perisylvian language "core" (Wernicke, 1874; Marie, 1917; Penfield and Roberts, 1959; Geschwind, 1965; Benson, 1985; Mayeux and Kandel, 1985). Lesions in or near this structure cause speech output disturbances characterized by phonemic paraphasias in repetition (Geschwind, 1965; Damasio and Damasio, 1980) and other phonological deficits (Caplan et al., 1995). One hypothesis that would reconcile these various findings is that the supramarginal gyrus may be involved in short-term storage of auditory information (Warrington et al., 1971; Caramazza et al., 1981; Paulesu et al., 1993). The tone decision task, which involved monitoring arbitrary sequences of up to seven tones, probably placed more demand on short-term auditory memory resources than did the semantic task, which involved familiar word stimuli. Relative lateralization of supramarginal gyrus activation to the right hemisphere is consistent with data showing right hemisphere dominance for short-term storage of nonlinguistic auditory information (Zatorre and Samson, 1991; Zatorre et al., 1994).

\section{REFERENCES}

Alexander MP, Schmitt MA (1980) The aphasia syndrome of stroke in the left anterior cerebral artery territory. Arch Neurol 37:97-100.

Alexander MP, Hiltbrunner B, Fischer RS (1989) Distributed anatomy of transcortical sensory aphasia. Arch Neurol 46:885-892.

Barrett AM (1910) A case of pure word-deafness with autopsy. J Nerv Ment Dis 37:73-92.

Benson DF (1985) Aphasia and related disorders: a clinical approach. In: Principles of behavioral neurology (Mesulam M-M, ed), pp 193-238. Philadelphia: Davis.

Binder JR, Rao SM, Hammeke TA, Frost JA, Bandettini PA, Hyde JS (1994a) Effects of stimulus rate on signal response during functional magnetic resonance imaging of auditory cortex. Cognit Brain Res 2:31-38.

Binder JR, Rao SM, Hammeke TA, Yetkin YZ, Jesmanowicz A, Bandettini PA, Wong EC, Estkowski LD, Goldstein MD, Haughton VM, Hyde JS (1994b) Functional magnetic resonance imaging of human auditory cortex. Ann Neurol 35:662-672.

Binder JR, Rao SM, Hammeke TA, Frost JA, Bandettini PA, Jesmanowicz A, Hyde JS (1995) Lateralized human brain language systems demonstrated by task subtraction functional magnetic resonance imaging. Arch Neurol 52:593-601.

Binder JR, Frost JA, Hammeke TA, Rao SM, Cox RW (1996a) Function of the left planum temporale in auditory and linguistic processing. Brain 119:1239-1247.

Binder JR, Swanson SJ, Hammeke TA, Morris GL, Mueller WM, Fischer M, Benbadis S, Frost JA, Rao SM, Haughton VM (1996b) Determination of language dominance using functional MRI: a comparison with the Wada test. Neurology 46:978-984.

Bogen JE, Bogen GM (1976) Wernicke's region - where is it? Ann NY Acad Sci 290:834-843.

Bookheimer SY, Zeffiro TA, Blaxton T, Gaillard T, Theodore W (1995) Regional cerebral blood flow during object naming and word reading. Hum Brain Mapp 3:93-106.

Bottini G, Corcoran R, Sterzi R, Paulesu E, Schenone P, Scarpa P, Frackowiak RSJ (1994) The role of the right hemisphere in the interpretation of figurative aspects of language. A positron emission tomography activation study. Brain 117:1241-1253.

Bracke-Tolkmitt R, Linden A, Canavan AGM, Rockstroh B, Scholz E, Wessel K, Diener H-C (1989) The cerebellum contributes to mental skills. Behav Neurosci 103:442-446.

Broca P (1861) Remarques sur le siège de la faculté du langage articulé; suivies d'une observation d'aphemie. Bull Soc Anat Paris 6:330-357.

Caplan D, Gow D, Makris N (1995) Analysis of lesions by MRI in stroke patients with acoustic-phonetic processing deficits. Neurology 45:293-298.

Caramazza A, Basili A, Koller J, Berndt R (1981) An investigation of repetition and language processing in a case of conduction aphasia. Brain Lang 14:235-271.

Carr TH, McCauley C, Sperber RD, Parmalee CM (1982) Words, pictures, and priming: on semantic activation, conscious identification, and the automaticity of information processing. J Exp Psychol Hum Percept Perform 8:757-777.

Cohen JD, Forman SD, Braver TS, Casey BJ, Servan-Schreiber D, Noll DC (1994) Activation of the prefrontal cortex in a nonspatial working memory task with functional MRI. Hum Brain Mapp 1:293-304.

Costello AL, Warrington EK (1989) Dynamic aphasia: the selective impairment of verbal planning. Cortex 25:103-114.

Cox RW (1996) AFNI: software for analysis and visualization of functional magnetic resonance neuroimages. Comput Biomed Res 29:162-173.

Craik FIM, Lockhart RS (1972) Levels of processing: a framework for memory research. J Verb Learn Verb Behav 11:671-684.

Crocker L, Algina J (1986) Introduction to classical and modern test theory. New York: Holt, Rinehart and Winston. Warburton E, Wise RJS, Price CJ, Weiller C, Hadar U, Ramsay S, Frackowiak RSJ (1996) Noun and verb retrieval by normal subjects. Studies with PET. Brain 119:159-179.

Damasio AR, Tranel D (1993) Nouns and verbs are retrieved with differently distributed neural systems. Proc Natl Acad Sci USA 90:4957-4960.

Damasio H (1981) Cerebral localization of the aphasias. In: Acquired aphasia (Sarno MT, ed), pp 27-50. Orlando, FL: Academic. 
Damasio H (1989) Neuroimaging contributions to the understanding of aphasia. In: Handbook of neuropsychology (Boller F, Grafman J, eds), pp 3-46. Amsterdam: Elsevier.

Damasio H, Damasio AR (1980) The anatomical basis of conduction aphasia. Brain 103:337-350.

Damasio H, Grabowski TJ, Tranel D, Hichwa RD, Damasio AR (1996) A neural basis for lexical retrieval. Nature 380:499-505.

Dejerine J (1892) Contribution à l'étude anatomo-pathologique et clinique des différentes variétés de cécité verbale. Comp Rend Séances Soc Biol 44:61-90.

Demb JB, Desmond JE, Wagner AD, Vaidya CJ, Glover GH, Gabrieli JDE (1995) Semantic encoding and retrieval in the left inferior prefrontal cortex: a functional MRI study of task difficulty and process specificity. J Neurosci 15:5870-5878.

Démonet J-F, Chollet F, Ramsay S, Cardebat D, Nespoulous J-L, Wise R, Rascol A, Frackowiak R (1992) The anatomy of phonological and semantic processing in normal subjects. Brain 115:1753-1768.

DeYoe EA, Bandettini P, Neitz J, Miller D, Winans P (1994) Functional magnetic resonance imaging (FMRI) of the human brain. J Neurosci Methods 54:171-187.

Fiez JA, Petersen SE, Cheney MK, Raichle ME (1992) Impaired nonmotor learning and error detection associated with cerebellar damage. Brain 115:155-178.

Fiez JA, Raichle ME, Balota DA, Tallal P, Petersen SE (1996) PET activation of posterior temporal regions during auditory word presentation and verb generation. Cereb Cortex 6:1-10.

Fisher RA, Cornish EA (1960) The percentile points of distributions have known cumulants. Technometrics 2:209-226.

Francis WN, Kucera H (1982) Frequency analysis of English usage: lexicon and grammar. Boston: Houghton Mifflin.

Freedman M, Alexander MP, Naeser MA (1984) Anatomic basis of transcortical motor aphasia. Neurology 40:409-417.

Frith CD, Friston KJ, Liddle PF, Frackowiak RSJ (1991) A PET study of word finding. Neuropsychologia 29:1137-1148.

Geschwind N (1965) Disconnection syndromes in animals and man. Brain 88:237-294, 585-644.

Geschwind N (1971) Aphasia. N Engl J Med 284:654-656.

Hart J, Gordon B (1990) Delineation of single-word semantic comprehension deficits in aphasia, with anatomic correlation. Ann Neurol 27:226-231.

Hart J, Lesser RP, Gordon B (1992) Selective interference with the representation of size in the human by direct cortical electrical stimulation. J Cognit Neurosci 4:337-344.

Henschen SE (1918) On the hearing sphere. Acta Oto-laryngologica $1: 423-486$.

Henschen SE (1920) Klinische und Anatomische Beitrage zur Pathologie des Gehirns. Stockholm: Nordiska Bokhandeln.

Hillis AE, Caramazza A (1991) Category-specific naming and comprehension impairment: a double dissociation. Brain 114:2081-2094.

Hinke RM, Hu X, Stillman AE, Kim SG, Merkle H, Salmi R, Ugurbil K (1993) Functional magnetic resonance imaging of Broca's area during internal speech. NeuroReport 4:675-678.

Howard D, Patterson K, Wise R, Brown WD, Friston K, Weiller C, Frackowiak R (1992) The cortical localization of the lexicons. Brain 115:1769-1782.

Kanshepolsky J, Kelley JJ, Waggener JD (1973) A cortical auditory disorder: clinical, audiologic and pathologic aspects. Neurology 23:699-705.

Keele SW, Ivry R (1990) Does the cerebellum provide a common computation for diverse tasks? Ann NY Acad Sci 608:179-211.

Kertesz A, Harlock W, Coates R (1979) Computer tomographic localization, lesion size, and prognosis in aphasia and nonverbal impairment. Brain Lang 8:34-50.

Kertesz A, Sheppard A, MacKenzie R (1982) Localization in transcortical sensory aphasia. Arch Neurol 39:475-478.

Kertesz A, Lau WK, Polk M (1993) The structural determinants of recovery in Wernicke's aphasia. Brain Lang 44:153-164.

Kim S-G, Ashe J, Georgopoulos AP, Merkle H, Ellermann JM, Menon RS, Ogawa S, Ugurbil K (1993) Functional imaging of human motor cortex at high magnetic field. J Neurophysiol 69:297-302.

Leiner HC, Leiner AL, Dow RS (1991) The human cerebrocerebellar system: its computing, cognitive, and language skills. Behav Brain Res 44:113-128.

Lichtheim L (1885) On aphasia. Brain 7:433-484.
Lüders H, Lesser RP, Hahn J, Dinner DS, Morris HH, Wyllie E, Godoy J (1991) Basal temporal language area. Brain 114:743-754.

Marcel AJ (1983) Conscious and unconscious perception: experiments on visual masking and word recognition. Cognit Psychol 15:197-237.

Marie P (1906) Revision de la question de l'aphasie: la troisième circonvolution frontale gauche ne joue aucun rôle spécial dans la fonction du langage. Sem Médicale 26:241-247.

Marie P (1917) Les aphasies de guerre. Rev Neurol 24:53-87.

Mayeux R, Kandel ER (1985) Natural language, disorders of language, and other localizable disorders of cognitive function. In: Principles of neural science (Kandel ER, Schwartz J, eds), pp 688-703. New York: Elsevier.

McCarthy G, Blamire AM, Rothman DL, Gruetter R, Shulman RG (1993) Echo-planar magnetic resonance imaging studies of frontal cortex activation during word generation in humans. Proc Natl Acad Sci USA 90:4952-4956.

Metter EJ, Hanson WR, Jackson CA, Kempler D, van Lancker D, Mazziotta JC, Phelps ME (1990) Temporoparietal cortex in aphasia. Evidence from positron emission tomography. Arch Neurol 47:1235-1238.

Millen SJ, Haughton VM, Yetkin Z (1995) Functional magnetic resonance imaging of the central auditory pathway following speech and pure-tone stimuli. Laryngoscope 105:1305-1310.

Mohr JP (1976) Broca's area and Broca's aphasia. In: Studies in neurolinguistics (Whitaker H, Whitaker H, eds), pp 201-236. New York: Academic.

Mohr JP, Pessin MS, Finkelstein S, Funkenstein HH, Duncan GW, Davis KR (1978) Broca aphasia: pathologic and clinical. Neurology 28:311-324.

Mufson EJ, Pandya DN (1984) Some observations on the course and composition of the cingulum bundle in the rhesus monkey. J Comp Neurol 225:31-43.

Naeser M, Hayward RW, Laughlin SA, Zatz LM (1981) Quantitative CT scan studies of aphasia. I. Infarct size and CT numbers. Brain Lang 12:140-164.

Nielsen JM (1946) Agnosia, apraxia, aphasia. Their value in cerebral localization. New York: Paul B. Hoeber.

Nobre AC, Allison T, McCarthy G (1994) Word recognition in the human inferior temporal lobe. Nature 372:260-263.

Ogawa S, Lee TM, Nayak AS, Glynn P (1990) Oxygenation-sensitive contrast in magnetic resonance image of rodent brain at high magnetic fields. Magn Reson Med 14:68-78.

Ogawa S, Tank DW, Menon R, Ellermann JM, Kim S-G, Merkle H, Ugurbil K (1992) Intrinsic signal changes accompanying sensory stimulation: functional brain mapping using MRI. Proc Natl Acad Sci USA 89:5951-5955.

Ojemann G, Ojemann J, Lettich E, Berger M (1989) Cortical language localization in left, dominant hemisphere. J Neurosurg 71:316-326.

Oldfield RC (1971) The assessment and analysis of handedness: the Edinburgh inventory. Neuropsychologia 9:97-113.

Pardo JV, Fox PT (1993) Preoperative assessment of the cerebral hemispheric dominance for language with CBF PET. Hum Brain Mapp 1:57-68.

Paulesu E, Frith CD, Frackowiak RSJ (1993) The neural correlates of the verbal component of working memory. Nature 362:342-345.

Penfield W, Roberts L (1959) Speech and brain-mechanisms. New York: Atheneum.

Petersen SE, Fox PT, Posner MI, Mintun M, Raichle ME (1988) Positron emission tomographic studies of the cortical anatomy of singleword processing. Nature 331:585-589.

Petersen SE, Fox PT, Posner MI, Mintun M, Raichle ME (1989) Positron emission tomographic studies of the processing of singlewords. J Cognit Neurosci 1:153-170.

Picard N, Strick PL (1996) Motor areas of the medial wall: a review of their location and functional activation. Cereb Cortex, in press.

Price CJ, Wise RSJ, Frackowiak RSJ (1996) Demonstrating the implicit processing of visually presented words and pseudowords. Cereb Cortex 6:62-70.

Raichle ME, Fiez JA, Videen TO, MacLeod AM, Pardo JV, Fox PT, Petersen SE (1994) Practice-related changes in human brain functional anatomy during nonmotor learning. Cereb Cortex 4:8-26.

Rao SM, Binder JR, Bandettini PA, Hammeke TA, Yetkin YZ, Jesmanowicz A, Lisk LM, Morris GL, Mueller WM, Estkowski LD, Wong EC, Haughton VM, Hyde JS (1993) Functional magnetic resonance imaging of complex human movements. Neurology 43:2311-2318. 
Rapcsak SZ, Rubens AB (1994) Localization of lesions in transcortical aphasia. In: Localization and neuroimaging in neuropsychology (Kertesz A, ed), pp 297-329. San Diego: Academic.

Rubens AB (1976) Transcortical motor aphasia. In: Studies in neurolinguistics (Whitaker H, Whitaker H, eds), pp 293-306. New York: Academic.

Rudge P, Warrington EK (1991) Selective impairment of memory and visual perception in splenial tumours. Brain 114:349-360.

Rueckert L, Appollonio I, Grafman J, Jezzard P, Johnson R, Le Bihan D, Turner R (1994) Magnetic resonance imaging functional activation of left frontal cortex during covert word production. J Neuroimaging 4:67-70.

Selnes OA, Niccum N, Knopman DS, Rubens AB (1984) Recovery of single word comprehension: CT-scan correlates. Brain Lang 21:72-84.

Sereno MI, Dale AM, Reppas JB, Kwong KK, Belliveau JW, Brady TJ, Rosen BR, Tootell RB (1995) Borders of multiple visual areas in humans revealed by functional magnetic resonance imaging. Science 268:889-893.

Shaywitz BA, Pugh KR, Constable T, Shaywitz SE, Bronen RA, Fulbright RK, Shankweiler DP, Katz L, Fletcher JM, Skudlarski P, Gore JC (1995) Localization of semantic processing using functional magnetic resonance imaging. Hum Brain Mapp 2:149-158.

Spearman C (1910) Correlation calculated from faulty data. Br J Psychol 3:271-295.

Sripanidkulchai K, Wyss JM (1986) Thalamic projections to retrosplenial cortex in the rat. J Comp Neurol 254:143-165.

Stuss DT, Benson DF (1986) The frontal lobes. New York: Raven.

Suzuki WA, Amaral DG (1994) Perirhinal and parahippocampal cortices of the macaque monkey: cortical afferents. J Comp Neurol 350:497-533.

Talairach J, Tournoux P (1988) Co-planar stereotaxic atlas of the human brain. New York: Thieme.

Tanaka Y, Yamadori A, Mori E (1987) Pure word deafness following bilateral lesions: a psychophysical analysis. Brain 110:381-403.

Toga AW, Jones AS, Rothfield JM, Woods RP, Payne BA, Huang C, Mazziotta JC, Cai R (1993) Anatomic variability as measured with a 3D reconstructed Talairach atlas. In: Quantification of brain function
(Uemura K, Lassen NA, Jones T, Kanno I, eds), pp 449-456. New York: Elsevier.

Valenstein E, Bowers D, Verfaellie M, Heilman KM, Day A, Watson RT (1987) Retrosplenial amnesia. Brain 110:1631-1646.

Van Orden GC (1987) A ROWS is a ROSE: spelling, sound, and reading. Mem Cognit 15:181-198.

Vogt BA (1976) Retrosplenial cortex in the rhesus monkey: a cytoarchitectonic and Golgi study. J Comp Neurol 169:63-97.

von Cramon DY, Hebel N, Schuri U (1988) Verbal memory and learning in unilateral posterior cerebral infarction. Brain 111:1061-1077.

Warburton E, Wise RJS, Price CJ, Weiller C, Hadar U, Ramsay S, Frackowiak RSJ (1996) Noun and verb retrieval by normal subjects. Studies with PET. Brain 119:159-179.

Warrington EK, Shallice T (1984) Category specific semantic impairments. Brain 107:829-854.

Warrington EK, Logue V, Pratt RTC (1971) The anatomical localisation of selective impairment of auditory verbal short-term memory. Neuropsychologia 9:377-387.

Wernicke C (1874) Der aphasische Symptomenkomplex. Breslau: Cohn, Weigert.

Wise R, Chollet F, Hadar U, Friston K, Hoffner E, Frackowiak R (1991) Distribution of cortical neural networks involved in word comprehension and word retrieval. Brain 114:1803-1817.

Woods RP, Cherry SR, Mazziotta JC (1992) Rapid automated algorithm for aligning and reslicing PET images. J Comput Assist Tomogr $16: 620-633$.

Zatorre RJ, Samson S (1991) Role of the right temporal neocortex in retention of pitch in auditory short-term memory. Brain 114:2403-2417.

Zatorre RJ, Evans AC, Meyer E (1994) Neural mechanisms underlying melodic perception and memory for pitch. J Neurosci 14:1908-1919.

Zola-Morgan S, Squire LR, Amaral DG, Suzuki WA (1989) Lesions of perirhinal and parahippocampal cortex that spare the amygdala and hippocampal formation produce severe memory impairment. J Neurosci 9:4355-4370. 